\title{
ESCRIBIR/INSCRIBIR LO FEMENINO EN EL DISCURSO
}

\author{
Manuel Ángel Vázquez Medel \\ Universidad de Sevilla
}

\begin{abstract}
"Toda mujer que quiera poseer una escritura que le sea propia no puede soslayar esta urgencia extraordinaria: inventar a la mujer" dice Annie Leclcrc. Sólo asesinando a la mujer que modeló el hombre podremos acceder a la especificidad de una escritura. Sólo clausurando el reino de la mujemiña, de la mujerhada de la casa, de la mujerdiosa del surrealismo, de la mujervirgen o madre del cristianismo, podrá advenir el reino de la mujertotal: obrera, madre, amante, política, escritora, la que sí soñó ese feminista llamado Rimbaud: "Cuando se haya roto la infinita esclavitud de la mujer, cuando ella viva para ella y por ella, también será poeta". Inventar a la mujer, ascetismo y purificación de la conciencia alternada, ideologizada, rechazo de desvalores que nos marcaron, como el de desconocernos entre nosotras mismas. Somos las herederas del mutuo desprecio y desconfianza que genera actitudes infraternas entre nosotras.
\end{abstract}

Teresa Leonardi Herrán: Piel de mujer, máscara de hombre.

En estos años iniciales del siglo XXI resulta ya inabarcable la bibliografía sobre la escritura femenina, la imagen de la mujer en la literatura, la posibilidad o imposibilidad de que la mujer pueda inscribirse en espacios discursivos creados y controlados por hombres, la importancia de tener en cuenta la diferencia de género en la construcción de la realidad, en el abordaje crítico de los productos culturales y, muy especialmente, de los literarios... Sin embargo, todo este volumen de (meta)discursos sobre la posibilidad/imposibilidad de un discurso femenino diferenciado y autónomo, de una escritura propia de mujer, son apenas una gota de agua en el inmenso océano de los espacios discursivos -tanto teóricos como creativos- gestados por/para hombres. Y lo que es peor: se siguen manteniendo en ámbitos de élite intelectual, sin apenas presencia entre ciudadanos y ciudadanas del mundo de la vida cotidiana, y con escasas o casi nulas implicaciones en las transformaciones de los cánones culturales y los procesos educativos o culturales. Tal vez, parafraseando a Marx en la tesis XI a Feuerbach, hasta ahora muchas mujeres (y algunos hombres) se han dedicado a interpretar y cuestionar su lugar en el mundo. Lo que hay que hacer es, simplemente, transformarlo. Aunque también ahora, en este hoy dominado por la koiné hermenéutica, en el que se ha desatado el conflicto de las interpretaciones, sepamos que interpretar el mundo es contribuir a su transformación.

Pensar en la actualidad sobre la inscripción de la mujer y de lo femenino en el discurso literario no es una actividad menor, marginal o sectorial de las ciencias de la literatura. Muy al contrario, afecta a todo un sistema de convicc10nes y creencias, de principios, de normas 
y de reglas, de mitos y de ritos, de dinámicas impositivas cuya consistencia hace tiempo que ponemos en cuestión. Los temas de la mujer no son sólo temas de/para mujeres, aunque nadie podrá arrebatarles ese derecho de construir su propia imagen y su propia identidad ni la capacidad para hacerlo, y de ayudar a los varones a la construcción de una nueva identidad no impositiva, no excluyente, no violenta. Son temas para la única posible humanidad futura, una humanidad en la que no se confunda lo antropocéntrico (pues ánthropos, aunque defectuosamente, implicaba por igual a mujeres y varones) con lo androcéntrico.

Por otra parte, el ámbito de lo literario constituye un territorio muy especial entre las creaciones culturales: al encontrarse en la escritura lo verbal y lo estético, asistimos al entrecruzamiento de las claves mismas del existir humano. Si la palabra es, como decía Heidegger, la morada del ser, en el proceso de control de los discursos verbales se ha mantenido durante siglos a la mujer a la intemperie, fuera de esa casa de tiempo y de silencio que va al río de la vida, según decía Juan Ramón Jiménez. Recluida en las moradas materiales, ha sido excluida de los espacios simbólicos que permiten una profunda y radical experiencia del ser como acontecimiento, como esamiento, como dinámica en el mundo de la vida. La mujer ha superado esta procelosa navegación a lo largo de siglos y siglos y ahora no es sólo Penélope, que teje y desteje a la espera, sino una nueva Odisea capaz de encontrar su propia identidad, su matria perdida.

\section{ENTRAR EN EL ORDEN DEL DISCURSO.}

¿Cómo entrar en este espacio de reflexión? ¿Cuál es el peaje que se nos exige? ¿Cuál el propósito que nos anima al contemplar los agónicos (y tantas veces, desgraciadamente, fallidos) intentos de mujeres del Mediterráneo y el Atlántico por trazar su huella en el discurso, por transgredir los límites que se les imponen desde la configuración del mundo de la vida generado desde los lenguajes y las lenguas naturales? Lenguas cruzadas por la memoria y el deseo, como afirmaba Carlos Fuentes a propósito de la lengua española. Pero una memoria selectiva y distorsiva, con una sistemática amnesia para lo femenino, y un deseo violentado desde la mirada impositiva masculina.

El acceso al orden del discurso condiciona, sin lugar a dudas, las posibilidades de nuestro discurrir. En nuestros días, por acción, reacción u omisión no hay más orden dominante del discurso que el androcéntrico, con una genealogía secular a sus espaldas, aunque ya afortunadamente forzado, agrietado, agotado, herido, sometido al discernimiento crítico que revela su falsa "naturalidad". En sus intersticios, pero fuertemente condicionados por la triple mitología patriarcal eurocéntrica, comienzan a florecer discursos que cuestionan su autoridad, su inevitabilidad, su conveniencia (incluso para los varones)... El principio de enantiodromía, por el que una realidad, en su extremo, se transforma en su contraria, juega a favor de la emancipación de la mujer una vez que hemos llegado, en muchos ámbitos, al paroxismo de lo androcéntrico y de la destrucción consiguiente.

Nos gusta pensar que las metáforas etimológicas que se encuentran en la noción de lo Mediterráneo (el espacio acuático y fluido en medio de las tierras que lo circundan) y lo Atlántico (la fuerza de los atlantes que sostienen el peso del universo, al tiempo que esa isla mítica rodeada de océano) están también en la base misma, en las raíces (o rizomas) de los empeños discursivos de las mujeres que han acometido la tarea de escribir e inscribir, en (y 
a través de) su escritura, su cuerpo (tantas veces negado), su deseo (casi siempre forzado y violentado), su identidad (construida desde fuera y estereotipada, falseada)... En efecto, se trata de la construcción de un nuevo territorio, de un interland, de un espacio humano (en el territorio abierto de una nueva humanitas) caracterizado por el in-between más que por la lógica de la exclusión y de las fronteras. Nos gustaría pensar que, más allá de las dinámicas de reproducción de lo mismo o de subrayamiento de la(s) diferencia(s) late la posibilidad de una ipseidad, tan equidistante de las lógicas identitarias androcéntricas como de las alteridades que conducen a alteraciones, a alienaciones, a enajenaciones. $\mathrm{Y}$ esta es una tarea de atlantes: han sido las mujeres, más que ese Atlas hijo de Jasón y de Climene, las que han sostenido la bóveda del cielo, desde su asentamiento en la tierra firme que, como madres reales o virtuales, las emparenta a la materia (mater/materia). Pero también huyamos, desde el principio, de una nueva mitología y una épica de la mujer y de lo femenino que exige el precio elevado de una responsabilidad inadmisible y de un peso que ha terminado aplastando a muchas mujeres de carne y hueso en sus esfuerzos de emancipación y dignificación. Como muy acertadamente afirma Rosa M. Rodríguez Magda (2003: '13) "Hurgar subsuelos, buscar esencias en un tiempo en que la metafísica hace mucho tiempo que dejó de contar, representa para nosotras la peor trampa. Hay que pelear, gozar, descansar o sonreír, ciertamente, pero a la altura de los tiempos".

$\mathrm{Y}$ estos tiempos son los del cuestionamiento radical del proyecto de modernidad y del orden androcéntrico (y muchas veces misógino) que llevaba en su seno a través del despliegue de una razón patriarcal. ¿Cómo plantear la escritura/inscripción de la mujer como sujeto y objeto autónomo del discurso? Si hasta ahora "ha sido el discurso masculino quien le ha dicho a la mujer lo que ella era, no porque lo descubriera, sino porque inventó y forjó ese 'su ser' en sus discursos, y eran los únicos donde ella pudo y hubo de reconocerse", sin embargo las mujeres no deben sentirse "desvalidas y huérfanas de sustancia, la carencia metafísica, por así decirlo, afecta a todas las criaturas de cielos y tierra, e incluso a las librescas y televisivas. Nuestra circunstancia, como la de todos aquellos seres periféricos a los que no se les ha permitido el acceso a la producción del saber, es solamente la de no haber podido ser dueñas de nuestros discursos. Pero no creáis que a los hombres, pobrecitos, les ha ido mejor. También ellos son una invención (...)" (Rodríguez Magda 2003: 17). Una y otra invención lo han sido de manera descarnada, alejada del orden real en que se despliega la concreta existencia de un ser humano como mujer o como varón. Por ello, ahora, hundidos todos los metarrelatos de legitimación, hemos de aprender a trazar la modesta narrativa de la vida cotidiana aprendiendo la lección de Scherezade. Se trata de inventar, en la acepción de "hallar o descubrir algo nuevo o no conocido" (DRAE), sólo que en este caso eso que hemos de hallar o descubrir es nuestra propia realidad sin más falsificaciones ni imposturas que las que, inevitablemente, exigen las construcciones discursivas. Por ello entendemos que ahora, en esta nueva encrucijada, la mujer descubra "el placer del simulacro", como afirma Rodríguez Magda. Pero eso sí: de los simulacros creados por ellas mismas y para ellas mismas, en relación de complementariedad y no de imposición con los simulacros creados por los varones. Y, sobre todo, sabiendo que se trata de simulacros, y no de una supuesta correspondencia, en el orden discursivo, con una pretendida realidad externa, sustantiva, objetiva. En este inventar e inventar-se, tras la recusación de una razón instrumental e impositiva, de un logos empobrecedor (el propio del falogocentrismo), reivindicamos la fuerza del mito, de la 
palabra que se dice y narra y nos funda en la precariedad del discurso; reivindicamos la fuerza de la imaginación y de la fantasía, porque las locas de la casa son las únicas que introducen un poco de cordura (de cor, corazón) en nuestras existencias.

Aunque ahora nos centramos fundamentalmente en la dinámica de la producción discursiva, una teoría cultural que desee cubrir al menos una parte importante de la complejidad de lo real no puede olvidar que, en el fondo, consideramos todo el circuito de la comunicación: no sólo las dinámicas que han impedido una inscripción propia de la mujer y de lo femenino en el espacio discursivo de la producción, cuestionando la supuesta transparencia que rige las escrituras y las lenguas (surcadas por la memoria y por el deseo) con que las escrituras se realizan. Se trata también de preguntarnos por los dispositivos complejos que presiden la circulación material y social de los discursos, preservando unos y condenando otros a la desaparición o al olvido, al tiempo que dotando a unos de prestigio y de valor social, en tanto que otros son colocados en algunos de los muchos márgenes que son necesarios para la construcción de vías centrales de circulación discursiva. Y se trata también -y en alguna medida, sobre todo- de replantear las estrategias, los dispositivos, los agenciamientos de apropiación discursiva que presiden las dinámicas lectoras.

Es preciso cambiar, pues, los horizontes de producción, circulación y recepción de los discursos, para que, al posibilitar la inscripción de la mujer y de lo femenino en la integridad de dichos procesos, sea posible de una vez por todas la emergencia de lo humano no como impostura y falsificación, por extensión de lo masculino (y también por pérdida de ciertas especificidades de lo masculino) hacia el ámbito del "hombre".

La circularidad de lo hermenéutico, que exige una toma de conciencia sobre las raíces mismas de la interpretación para contestar la transparencia de lo interpretado, se extiende también a la circularidad de los procesos discursivos, con principios de acción y reacción que implican no sólo escritura y lectura como actos diferenciados pero fuertemente imbricados, sino también todos los sutiles mecanismos de institucionalización discursiva. Y aunque nuestro pensar se dirija ahora a uno de esos polos (el de la escritura), no olvidaremos en ningún momento que el ejercicio y el oficio de escribir se nos dan desde más complejas in(ter)determinaciones discursivas.

\section{HACIA UNA EPISTEME DISCURSIVA FEMENINA: UN PROYECTO INVESTIGADOR.}

Si para Foucault la palabra epistémè designaba el "conjunto de relaciones y leyes de transformación que unifican todas las prácticas discursivas en un período de tiempo determinado" o incluso "un período de tiempo dentro del cual está localizado un conjunto determinado de regularidades discursivas" (M. Margaroni, en Taylor-Wynquist 2002: 113), es evidente que la inscripción, a través del proceso de escritura, de una mujer en el orden del discurso, implicaba la aceptación de ese conjunto de relaciones y leyes, la entrada en un conjunto de regularidades discursivas al precio de renunciar a su propia realidad (especialmente a su propia corporeidad vivida desde dentro y a su propia identidad construida autónomamente), puesto que las diversas epistemes que se han producido hasta la actualidad implicaban la existencia de un orden androcéntrico. En su interior era imposible la emergencia de la mujer y de lo femenino desde la autonomía (ya que las representaciones de la mujer, sea como sujeto, sea como objeto de la escritura implicaban siempre una heteronomía, una consideración de otredad, sin espacio para la mismidad y la 
identidad), y las dinámicas de escritura establecían esos espacios marginales, desde los que vemos que se cuestiona esa centralidad de un orden discursivo. Como afirma Craig Owens (1985), al subrayar el carácter masculino del sujeto de la representación en la modernidad, "entre las prohibidas de la representación occidental, a cuyas representaciones se les niega toda legitimidad, están las mujeres. Excluidas de la representación por su misma estructura regresan a ella como una figura, una representación de lo irrepresentable (la naturaleza, la verdad, lo sublime, etc.)".

Los diversos intentos de la escritura femenina hasta la actualidad (exceptuando aquellos que aceptaban sin más el orden del discurso androcéntrico) marcan las fracturas y las líneas de fuga desde esa imposición epistémica hacia la creación de un nuevo orden discursivo que aún no ha podido exhibir del todo su carácter propio y alternativo. Se trata, en efecto, de una doble tarea a la vez deconstructiva y constructivista: la eliminación de las imágenes y estereotipos de la mujer y de lo femenino creadas desde un imaginario patriarcal es absolutamente imprescindible para la aparición de la mujer y las mujeres, de lo femenino en toda su complejidad, no desde otra lógica, sino desde una lógica otra, no desde otra discursividad, sino desde una discursividad otra.

Sin lugar a dudas es imprescindible un replanteamiento de la ratio dicendi que organizaba tanto las retóricas formales del mundo clásico hasta el siglo XVIII, como las retóricas informales y las antirretóricas del proceso de despliegue de la modernidad literaria. Esa ratio y ese ordo establecían como naturales dinámicas de prevalencia, de imposición, de exclusión, desde el lenguaje y en el lenguaje.

El alcance y el estado de estas inscripciones discursivas y del cambio de esa ratio que nos revelaría una nueva epistémè emergente, podría evidenciarse a través de una indagación detallada de los rasgos de la inventio, con la presencia de nuevos factores tematológicos, la tendencia a la ruptura de la tópica convencional y la creación de nuevos lugares discursivos, topoi; una nueva sintaxis discursiva, una dispositio más abierta y versátil, más policéntrica, más fragmentaria; una elocutio más libre, pero que no acaba de configurar estilos expresivos claramente identificables (aunque tal vez también consista en eso la inscripción de lo femenino en el discurso: la huida de identidades fijas, inamovibles)... Finalmente, nuevos rasgos de la memoria y de la actio, nos pondrían en la pista de una nueva pragmática de la comunicación literaria impulsada por la presencia autónoma de mujeres como sujetos y objetos de una enunciación y unos enunciados no impuestos desde las epistemes androcéntricas. Sabemos que también la dinámica de recuerdos y olvidos está regida fatalmente por las marcas de género.

\section{Mujer/Femenino.}

Resultan imprescindibles algunos asentamientos previos: ¿hablamos de la inscripción de la mujer (o mejor aún, de mujeres concretas) en la escritura, o bien de la inscripción de lo femenino? Es evidente que, desde ciertas posiciones feministas, se nos podría decir que tal pregunta y -sobre todo- tal disociación son propias del discurso androcéntrico. Y en cierto sentido es verdad: el gesto más ridículo de los hombres (varones) para conservar cierta dignidad y cierto futuro, ante un pasado y un presente de ignominia de género, podría ser la disociación mujer/femenino, a fin de reivindicar la dimensión femenina presente en los hombres (anima, según Jung), al tiempo que recusar las impostaciones masculinas 
(provenientes de su animus) que adoptan muchas mujeres. A muchos investigadores -y sobre todo, investigadoras- no les ha pasado por alto el hecho de que una visión tal de lo masculino o de lo femenino, que pasara por su ontologización, y más allá de ella por la afirmación metafísica de los géneros (aunque fuera a través de la inversión de los valores tradicionalmente atribuidos), seguiría siendo una precaria victoria de lo masculino, ahora asumido por las mujeres. Y esto es también cierto.

Lo cual nos obliga a una reflexión sobre el alcance del par varón/mujer, masculino/femenino y sobre las trampas insalvables que plantea, ya que no es -sin másposible afirmar que la condición de mujer es biológica, mientras que los roles y sentimientos asociados a lo femenino son construcciones culturales y, por tanto, sociales y contingentes. Lo natural y lo sociocultural se ofrecen, en el caso de los seres humanos, como co-determinaciones difícilmente disociables. Lo humano, como lo masculino o lo femenino, se nos presentan como disposiciones biológicas que se encarnan y desarrollan en contextos históricos y socioculturales diversos. Así lo reconocen Pearson-Turner-Todd (1993: 27): "creemos que el sexo, biológicamente hablando, converge con el género, de forma que ambos no pueden separarse con facilidad. A pesar de que la mayoría de gente piensa que el sexo es un atributo relativamente simple e invariable, la verdad es que siempre estará afectado por las influencias del aprendizaje social, aprendizaje al que nosotros denominamos género. Algunos investigadores han decidido denominar, a esta misma interrelación, el sexo adquirido".

Analicemos las principales alternativas ante el problema planteado:

1. Por un lado, las dinámicas de dominación, exclusión, afirmaciones identitarias, etc. se han basado tradicionalmente en la metafisica de los sexos y de los géneros: el hombre es..., la mujer es... (lo cual, de inmediato, desde el jusnaturalismo plantea también el debería ser/no ser y más allá aún el tiene que ser/no ser..., atribuyendo un rol patémico -un sistema de sentimientos- y un rol temático -un sistema de acciones- a los seres humanos por el hecho de ser varones o mujeres. Por supuesto, tales atribuciones, tales construcciones de imaginarios sociales, han sido sistemáticamente elaboradas por varones. La conexión sexo-género (e incluso orientación u opción sexual) era la coartada para el montaje de todo un sistema educativo, un sistema social, un sistema económico, cultural y político basado en la falacia de una diferencia axiologizada (puesta en valor) y convertida de inmediato en discriminación. Buena parte de la escritura realizada por mujeres hasta el siglo XX responde a la aceptación sin más de estas lógicas (falogocéntricas), hasta el punto de la simulación de la condición sexual para entrar en el canon y en el circuito de la comunicación literaria. Es justo reconocer, con todo, que más allá de la imposición y más acá de la aceptación de una ratio y un ordo masculinos, laten importantes dimensiones que ni siquiera la imposición del discurso puede acallar. La diferencia fluye incluso allí donde sólo se ha querido ver la discriminación. Lo subversivo, en este caso - puesto que no nos es dado transformar la historia factual, los hechos brutos- es la lectura peculiar, la interpretación de un pasado que puede gravitar sobre el presente de modo bien distinto, como territorio de una reflexión emancipadora, más que como reproducción de una imposición que tiende a perpetuarse. La nueva hermenéutica no es ya una doxástica que impone sentidos e 
interpretaciones, sino de libera de sus significados y sentidos distorsivos las acciones y los discursos del pasado.

2. Por otra parte, las respuestas desde cierto feminismo de la igualdad, suponiendo sin duda un extraordinario avance sobre el sexismo de la discriminación, parecía dejar, en algunas de sus opciones, inalterado el núcleo mismo desde el que se establecían las distinciones de sexo y género: la mujer podía ser igual al hombre siempre que aceptara y se sometiera (más o menos) a las reglas del juego creadas por éste, que permanecían incuestionadas sub specie naturalitas, bajo la forma de una falsa naturalidad. Es decir: una mujer puede ser exactamente igual que un hombre, siempre que se mueva en el sistema social creado por éste siguiendo sus reglas, pautas, normas... Es decir: una mujer puede llegar a ser presidente de gobierno (vg.: Margaret Thacher) siempre que siga las pautas de conducta que un hombre aplicaría en su caso, porque éstas son las correctas y naturales. Gracias a estos planteamientos hemos tenido o tenemos en nuestro país mujeres alcaldesas, ministras, presidentas del Congreso... o escritoras que a veces prestan un flaco servicio a la causa de la mujer, aunque desde luego, aunque sólo sea por su visibilidad y por recordarnos que también las opciones de las mujeres están atravesadas por líneas ideológicas, se trata de algo preferible a la no presencia de la mujer. Y uno de los problemas más graves de este tipo de planteamientos, unido al de los estereotipos de la femineidad, se encuentra en la renuncia a acciones o sentimientos cuya "naturaleza femenina" es, sin duda, discutible.

3. Desde el feminismo de la diferencia la cuestión es, en primer lugar, rechazar una dinámica y una dialéctica impuestas por los hombres: la construcción de la mujer como otra realidad humana, y por tanto, su ontologización. Desde esta perspectiva, se subvierte axiológicamente el sistema: se proclama el derecho a la existencia de la otra como misma, e incluso más allá, el derecho a crear su propia dinámica identitaria. Precisamente allí donde se niega el derecho a la construcción de un sujeto y una subjetividad (que ya no será el sujeto fuerte de la modernidad) emerge la posibilidad de constituirse en el nuevo sujeto social dominante: "¿Somos acaso las mujeres el nuevo 'sujeto histórico'? Posiblemente. Yo estaría dispuesta a afirmarlo al comprobar la multitud de grupos de mujeres que en distintos frentes de lucha se están organizando. Sí, curiosamente, por el hecho de ser mujeres con una necesidad y un deseo de cambiar las cosas (...) Tal vez sea el momento de construir frentes comunes y plurales (no es contradictorio) de mujeres como encarnación real y simbólica de otro mundo posible" (V. Sendón 2003: 7).

Es evidente que muchas otras posiciones intermedias son posibles, pero en ninguna de ellas se resuelve satisfactoria y definitivamente el problema que hemos planteado. Y no se resuelve porque no es posible, de la noche a la mañana, cambiar un complejo sistema de relaciones, en el que nos encontramos previamente implicados.

$\mathrm{Si}$ esto es cierto en cualquier caso, cuando acentuamos las dimensiones discursivas se nos hace aún más patente. Retomemos nuestras preguntas iniciales desde los supuestos de la Teoría del Emplazamiento. 


\section{LA MUJER Y LO FEMENINO DESDE LA TEORÍA DEL EMPLAZAMIENTO.}

La Teoría del Emplazamiento, como nueva propuesta de comprensión de la compleja realidad en que nos encontramos insertos, sin situarse ni por encima ni fuera del orden implicado desde el que realizamos nuestra contemplación (y queremos reconocer éste como un rasgo femenino, frente a lo diairético, separador y abstracto de las visiones masculinas) es especialmente importante para plantear el problema de la inscripción de la mujer y de lo femenino en el discurso literario. En uno de los textos fundacionales se afirma: "La Teoría del Emplazamiento es constitutivamente mestiza o -mejor aún- criolla (Glissant). Rechaza la pureza (como acrisolamiento de la vida en el fuego de la intransigencia) y quiere ser conocimiento dinámico y relacional, saber-para-la-vida. Denuncia la dictadura de la información controlada por unos pocos y el conocimiento construido al servicio de intereses minoritarios. Reivindica la dimensión femenina, preterida por siglos de pensamiento androcéntrico, impositivo, de confrontación, y reclama la necesidad actual de un pensamiento más ginecocéntrico, un imaginario femenino de alianza y benevolencia, que lleve a un nuevo horizonte antropocéntrico (ahora sí, integración de lo masculino y de lo femenino), a un nuevo y gran pacto por una nueva humanitas, más allá de la humanidad entendida como un conjunto de normas para el parque humano (Sloterdijk), aunque hemos de saber que humanizar supone inmediatamente el riesgo de programar en determinados conocimientos, actitudes y comportamientos las mentes que deben ser integradas a la vida social. Pero el verdadero humanismo abre siempre el necesario espacio crítico desde el cual las mentes así formadas pueden (y deben) replantear lo que han recibido, casi las bases mismas de su discurrir en el seno de una sociedad" (Vázquez Medel 2003: 29-30).

Cada uno y cada una de nosotros (y me gustaría que este fuera un nosotros plural, que no elimina la diferencia pero que sí hace posible la presencia de lo masculino y lo femenino en esencial igualdad) se encuentra emplazado en un lugar, en un tiempo, en unas coordenadas personales que son tanto materiales como simbólicas y que, lejos de ser estáticas cambian a cada instante, subrayando ese carácter discursivo de todo lo existente: todo corre, todo discurre, todo se transforma, en un universo que contemplamos no desde la óptica de las esencias metafísicas inmutables, sino desde una ontología del acontecer, en la que cada ser se nos ofrece como suceso encarnado.

Encarnados, instados, emplazados en el orden de lo material y en el de lo simbólico, en ese territorio de frontera que es el propio de lo humano, cada uno de nosotros nos constituimos en apertura relacional con los otros, no como mónadas, sino como seres dinámicos, cambiantes. Pero es indudable que siempre nos desplegamos desde una situación concreta, desde un conjunto de predeterminaciones, de condicionamientos, desde un horizonte comprensivo e interpretativo que cualifica nuestra proyección tensiva sobre el mundo.

Y ese horizonte comprensivo e interpretativo ha sido en gran medida creado por y para hombres, con una sistemática exclusión o inclusión, a través de redes de dominio y de control sobre las mujeres. Tal es nuestro punto de partida. Y no es posible hacer tabula rasa, porque sin precomprensión no hay comprensión, ni sin prejuicio -en el sentido más amplio- hay juicio. Sabemos que incluso el esfuerzo de demolición de un sistema de pensamientos, de sentimientos, de mediaciones materiales para que se encarnen en 
lenguajes quedaría fatalmente marcado por tales predeterminaciones. Es una de las claves del círculo hermenéutico, que podemos irresponsablemente negar, pero que seguirá vivo y presente a través de nuestras negaciones.

La Teoría del Emplazamiento, al destacar la importancia de la otredad, de la alteridad ( $\sin$ llegar al extremo de la alteración, de la alienación, de la enajenación), pero también de la mismidad, de la identidad, tanto propia como compartida, establece las bases para una nueva inscripción de lo femenino en el discurso, observando esa dimensión tensiva: construyendo las identificaciones dinámicas y cambiantes que le fueron negadas y estableciendo el espacio de la alteridad no desde un orden externo, sino desde el interior de la encarnación discursiva. Es lo que quisimos expresar con estas palabras: "La exacerbación de la identidad conduce a las construcciones identitarias que afirman lo propio por negación de lo ajeno, a las identidades asesinas (Maaluf). Pero el déficit de identidad, la apertura al otro y a los otros, la excesiva alteridad, puede desembocar en graves "alteraciones": a la alienación que surge como consecuencia de la explotación, la dominación o la opresión (Marx-Engels), a la enajenación mental como respuesta a la imposibilidad de aceptarnos nosotros mismos (Freud). Por ello es necesario construir ese quid pro quo, ese ideal de la ipseidad (Ricoeur), en el que es posible vivir la dinámica de identidad (no esencialista, sino procesual, sin cristalizar, más bien identificaciones funcionales) y diferencia (que no se transforma en discriminación, en oposición, en exclusión)" (Vázquez Medel 2003: 25-26).

Y en ese empeño por redescubrir ese Tú constitutivo de lo humano (que nunca fue la mujer para el varón) siguiendo las huellas de Martin Buber podemos suscribir estas palabras que se refieren al planteamiento del problema en Helène Cixous: "Para Cixous, la escritura misma es el lugar del otro, donde las identidades son cuestionadas y cambiadas. La escritura de la mujer provocará por sí misma un regreso a su cuerpo confiscado, la puerta de entrada al inconsciente. La escritura del cuerpo, a través de una desestabilización de la distinción habla/escritura y el retorno de lo reprimido, servirá para perturbar las estructuras binarias y jerárquicas, pues esta escritura significa la 'no exclusión'. Cixous insiste en el hecho de que esta 'práctica femenina de la escritura' no puede definirse ni teorizarse, pues hacerlo sería un signo de retorno a los viejos sistemas de la lógica" (Danielle Clarke, en M. Payne 2002: 88). Sólo nos queda, pues, asistir en el ámbito de la construcción directa de lo discursivo a ese asalto pendiente no en ninguna Bastilla ni en ningún Palacio de Invierno, sino en la Semiosfera, en el Imaginario Social, en el bastión del orden de los discursos. Si esta nueva revolución alcanza a realizar su sentido no encontraremos al final sólo una mujer libre, autónoma, emancipada, sino también un varón libre de la esclavitud a su imposición y su poder, y la posibilidad de la pareja humana, más allá de las determinaciones de sexo, género, opción sexual.

\section{COlOfón: EUROPA TIENE NOMBRE DE MUJER}

Lo mediterráneo y lo atlántico no se reducen a lo europeo, aunque sin duda Europa ha marcado la realidad del Mare Nostrum y de ambas orillas del Atlántico. Desde una lógica y una dinámica de la inclusión y no de la exclusión, de la apertura y no del cierre, de la interrelación comunicativa equilibrada y no desde la imposición, me gustaría ofrecer una última reflexión, porque entiendo que el único futuro posible de una Europa que vuelve 
derrotada y horrorizada del sueño de la razón moderna, que produjo monstruos, pasa por la consolidación de un imaginario femenino de alianza, frente al imaginario masculino de confrontación, de exclusión, de poder, de prevalencia, de identidades asesinas. Y esto tiene mucho que ver con la necesidad y la urgencia de crear discursos en los que se cuestione el orden androcéntrico como orden natural o único posible, y emerjan otros discursos que sean también discursos otros.

Que Europa no es sólo una poderosa realidad geográfica e histórica (un espacio y un tiempo compartidos), con todo tipo de implicaciones económicas, sociales, políticas y culturales, sino sobre todo un proyecto, es algo que quedó evidenciado en una entrevista a Nicole Fontaine, entonces presidenta del Parlamento Europeo. Desde su título, "Tenemos que reinventar Europa" queda claro que nada hay de inmovilista en el proyecto de construcción del nuevo espacio europeo, cuyas características no pueden ser las de ningún pasado, por muy fascinante que sea. Se trata, en efecto, de impulsar un espacio colectivo de convivencia, una comunidad, en la que la pluralidad no implique fragmentación, ni la integración ninguna nueva forma de integrismos.

En un momento de reivindicaciones identitarias excluyentes y contrapositivas, de llamadas anacrónicas a las patrias y a los patriotas, de violencia terrorista, Nicole Fontaine muestra muy bien la vía de la construcción de una matria europea (antesala de nuestra única matria Gea o Gaia) como comunidad de valores compartidos y -siemprecríticamente replanteados. Por ello, esta Europa no puede ser construida por los políticos al margen de los ciudadanos, ni puede responder al imaginario social androcéntrico, de confrontación, que presidió la época de los nacionalismos en Europa. Sólo un nuevo imaginario social de alianza, impregnado de valores hasta ahora considerados como femeninos, puede proporcionar una sólida esperanza para esta nueva Europa, la asiática hija del rey fenicio Agenor, que ahora debe resistirse a su rapto por el Zeus-Toro, hoy dios todopoderoso del dinero, para llegar a ser, más allá de la Europa de los mercados y los mercaderes, la Europa de los pueblos y de los ciudadanos y ciudadanas. Una Europa que debe ser construida gracias -también- a la inscripción de la mujer y de lo femenino en el discurso. En todo tipo de discursos.

\section{REFERENCIAS BIBLIOGRÁFICAS}

AMORÓS, Celia (2000): Tiempo de feminismo. Sobre feminismo, proyecto ilustrado y posmodernidad, Madrid, Cátedra.

JOHNSON, Mark (1991): El cuerpo en la mente. Fundamentos corporales del significado, la imaginación y la razón, Madrid, Debate.

MARTÍN GONZÁLEZ, Matilde (2003): Discursividad sexual y poder disciplinario: una visión foucaultiana en la obra de tres poetas norteamericanas, La Laguna, Universidad de la Laguna.

OSBORNE, Raquel (1993): La construcción sexual de la realidad. Un debate en la sociología contemporánea de la mujer, Madrid, Cátedra.

OWEN, Craig (1985): La posmodernidad, Barcelona, Kairós. 
PAYNE, Michael (2002): Diccionario de teoría critica y estudios culturales, Buenos Aires, Paidós.

PEARSON, Judy C.- Turner, Lynn H. - Todd-Mancillas, W. (1993): Comunicación y género, Barcelona, Paidós.

PULEO, Alicia H. (1992): Dialéctica de la sexualidad. Género y sexo en la filosofía contemporánea, Madrid, Cátedra.

RODRÍGUEZ MAGDA, Rosa María (2003): El placer del simulacro. Mujer, razón y erotismo, Barcelona, Icaria.

SENDÓN DE LEÓN, Victoria (2003): Mujeres en la era global. Contra un patriarcado neoliberal, Barcelona, Icaria.

TANNEN, Deborah (1996): Género y discurso. Barcelona, Paidós.

TAYLOR, Víctor E. - Winquist, Charles E. (eds.) (2002): Enciclopedia del Posmodernismo, Madrid, Síntesis.

VÁZQUEZ MEDEL, Manuel Ángel (1999): Mujer, Ecología y Comunicación en el nuevo horizonte planetario, Sevilla, Mergablum.

VÁZQUEZ MEDEL, Manuel Ángel -Arriaga, Mercedes (eds.)(2002): Mujer, Cultura y Comunicación: Realidades e Imaginarios, IX Simposio Internacional de la Asociación Andaluza de Semiótica, Sevilla, Alfar.

VÁZQUEZ MEDEL, Manuel Ángel (dir.) (2003): Teoría del emplazamiento: aplicaciones e implicaciones, Sevilla, Alfar.

ZAVALA, Iris M. y otros (1993): Iris M. Zavala. Una poética del imaginario social, núm. 145 de Anthropos. Revista de documentación científica de la cultura. 
